\begin{abstract}
Resumo
Esta pesquisa teve por objetivo o estudo das cenas temidas na aprendizagem no atendimento grupal psicopedagógico de crianças e adolescentes de 11 a 13 anos. A partir da identificação das "cenas temidas" no grupo, foi possivel refletir sobre os obstáculos que os participantes encontraram. Coube à equipe estruturar atividades lúdicas que provocassem a confrontação do participante com ele mesmo e em relação ao outro, faz̧endo-o refletir sobre suas dificuldades, e provocando-os a assumirem suas capacidades criativas. Relatamos algumas cenas e de que forma foram pensadas pela equipe. Percebeu-se a importância da intervenção psicopedagógica grupal sobre as manifestações de ocultamento do sujeito criador/ autor, que foram as que mais caracterizaram os modos como os participantes se relacionavam com o objeto de conbecimento.

Descritores: aprendizagem; cenas temidas do aprender; psicopedagogia; criança; adolescentes.
\end{abstract}

\section{TRATAMENTO GRUPAL PSICOPEDAGÓGICO E AS CENAS TEMIDAS NA APRENDIZAGEM DE CRIANÇAS E ADOLESCENTES}

\author{
Regina Orgler Sordi \\ Fernanda Martins Marques \\ Sandra Laura Frischenbruder Sulzbach \\ Renata Borba Pires \\ Carlos Henrique Kessler
} Serviço de Psicopedagogia da Clínica de Atendimento
Psicológico da Universidade Federal do Rio Grande do Sul (UFRGS), Porto Alegre, RS, Brasil.

- - Psicóloga. Psicoterapeuta de orientação psicanalítica. Mestre em Psicologia pela Universidade Federal do Rio Grande do Sul (UFRGS). Integrante da equipe da Clínica de Atendimento Psicológico da Universidade Federal do Rio Grande do Sul (UFRGS), Porto Alegre, RS, Brasil.

- a - Psicóloga. Mestre em Psicologia pela Pontifícia Universidade Católica do Rio Grande do Sul (PUC-RS). Integrante da equipe da Clínica de Atendimento Psicológico da Universidade Federal do Rio Grande do Sul (UFRGS), Porto Alegre, RS, Brasil.

- - - Aluna de graduação em Psicologia pela Universidade Federal do Rio Grande do Sul (UFRGS). Bolsista de iniciação científica pela Universidade Federal do Rio Grande do Sul do Programa de Apoio a Planos de Reestruturação e Expansão das Universidades Federais (BIC/UFRGS-REUNI), Porto Alegre, RS, Brasil.

- a - " Professor e diretor da Clínica de Atendimento Psicológico da Universidade Federal do Rio Grande do Sul (UFRGS). Psicanalista da Associação Psicanalítica de Porto Alegre (APPOA), Porto Alegre, RS, Brasil. 
Os obstáculos fazem parte da vida; diante deles, temos duas possibilidades: transformá-los em impedimentos ou em oportunidade de autoria.

Jorge Gonçalves da Cruz, 2001

\section{Introdução}

$A($ aprendizagem e suas vicissitudes têm sido tema de nossas pesquisas há mais de duas décadas. Entretanto, pouco tem sido pesquisado e publicado sobre o tratamento psicopedagógico grupal com crianças e adolescentes com problemas de aprendizagem. O projeto de atendimento grupal psicopedagógico teve o objetivo precípuo de aliar $\mathrm{o}$ atendimento a crianças e adolescentes com dificuldades de aprendizagem à pesquisa sobre cenas do aprender que sejam por eles vividas como "temidas" e/ou que expressem obstáculos por eles enfrentados.

Para tanto, optamos pelo trabalho terapêutico grupal, considerado uma modalidade de tratamento que, por seu enquadre, privilegia vários aspectos relacionados ao aprender: permite a necessária circulação dos personagens que ensinam e aprendem; facilita a expressão dos temores e dificuldades enfrentados e que obstaculizam o livre trânsito das aprendizagens; ajuda a valorizar a função positiva da ignorância ${ }^{1}$, num contexto em que os lugares de "não saber" são cambiáveis e trabalhados clinicamente; relativiza a culpa pelo erro, permitindo uma apropriação mais sadia do "não saber" como motor para o "saber"; trabalha, de forma mais ágil, os diferentes significados das dificuldades de aprendizagem, através da circulação de situações, sentimentos e reflexões que o grupo possa desenvolver; facilita a troca entre os pares, que passam a funcionar como figuras ao mesmo tempo "ensinantes" e "aprendentes".

Essa pesquisa teve início no ano de 2011, na Clínica de Atendimento Psicológico da Universidade Federal do Rio Grande do Sul (UFRGS) e em uma escola pública, onde foi desenvolvido um trabalho com grupos de crianças cujo objetivo terapêutico foi o de possibilitar a recuperação do prazer de aprender e a autonomia do exercício da inteligência (Fernández, 1989). Para fins de pesquisa, realizamos um levantamento das cenas mais frequentes trazidas pelos jovens e que diziam respeito às suas dificuldades de aprendizagem. Uma vez realizado o levantamento das cenas temidas relacionadas ao 
aprender, as pesquisadoras formaram um arquivo de cenas como base para a futura criação de uma série de jogos e atividades, que, por sua vez, poderão ser utilizados em outros grupos, onde temores semelhantes possam emergir.

Desse modo, pretendeu-se inaugurar uma forma inovadora de enfrentar os problemas de aprendizagem, aliando a agilidade nos atendimentos ao aprofundamento das questões que dificultam os jovens em seu acionar escolar.

\section{Tratamento grupal psicopedagógico: entre o espaço do brincar e o espaço do aprender - origens do trabalho grupal psicopedagógico}

O trabalho grupal com crianças e adolescentes, no âmbito psicopedagógico, tal como concebemos, imprime certa continuidade com atividades que são naturais ao ser humano em seus processos de desenvolvimento cognitivo e emocional.

Partimos da ideia de que o espaço do brincar e o espaço do aprender são simultâneos e participam do que consideramos manifestações de saúde na aprendizagem. Não estamos homologando o brincar com o aprender, pois se tratam de dois fenômenos diferentes. O brincar não impõe as mesmas legalidades que o aprender. Uma criança que queira brincar de nadar pode fazer a mímica com os braços no ar, imitando os nadadores.
Aprender a nadar, todavia, impõe uma série de resistências, a começar, pela água, bem como, exercícios de respiração, coordenação e sincronia corporal, etc. Quando dizemos que o espaço do aprender e o espaço do brincar são simultâneos, referimo-nos ao espaço mental, que é o mesmo para ambos os fenômenos. $\mathrm{O}$ espaço mental do brincar pressupõe a capacidade de transformação. A criança pequena, sem que ninguém a ensine, toma objetos em suas mãos e faz de conta que são outra coisa. Uma caneta pode se converter num avião, uma pequena caixa pode se transformar em um trem e assim por diante. Entretanto, onde predomina a saúde, a caneta volta a ser uma caneta e a caixa volta a ser uma caixa, uma vez que a capacidade simbólica é a responsável por fazer o trânsito entre a fantasia e a realidade.

No aprender, o conhecimento apresenta-se como causa e impõe certas legalidades. Uma letra qualquer é sempre igual a ela mesma, assim como um número sempre expressa a quantidade que ele representa. Entretanto, ao assimilar a legalidade do conhecimento, segue-se a capacidade de interpretação, manifestando-se o espaço mental do aprender. O conteúdo assimilado precisa fazer sentido para aquele que o internaliza. É nessa operação de fazer sentido que o espaço mental do aprender associa-se ao espaço mental do brincar.

Cada criança, cada ser humano aprendente, precisa interpretar os 
conteúdos do conhecimento de acordo com suas próprias capacidades objetivas e estados subjetivos. O trabalho grupal psicopedagógico encontra-se tramado com a ideia de criação de um espaço mental lúdico, cuja tarefa consiste em transformar a aprendizagem em algo que faça sentido para o sujeito.

O lúdico sempre acompanhou o desenvolvimento das áreas psicológicas e psicopedagógicas. No campo psicanalítico, Freud (1909) propôs ao pai do pequeno Hans que auxiliasse o menino com as representações sobre seus medos de cavalos. Klein (1953) afirmava que, através do brincar, as crianças expressavam seus conflitos e a forma como se defendiam dos mesmos. Winnicott (1975) dispunha-se a desenhar com a criança numa folha de papel. Dolto (1981) oferecia massa de modelar para propiciar que a criança armasse histórias, cenas, etc.

O movimento grupal, com crianças e adolescentes, tem suas raízes nas técnicas psicodramáticas, originárias de Moreno, tal como citado por Anzieu (1982), muito embora esse pioneiro trabalhasse apenas com adultos. As ideias de Moreno chegaram à França por volta de 1946 (Anzieu, 1982). Naquele país, a psicologia infantil apresentava enormes avanços com o pioneirismo de Jean Piaget no campo da epistemologia genética e o impulso em neuropsicologia infantil (Ajuriaguerra), bem como a psicanálise de crianças (Lebovici e Diaktine, entre outros). Foi naquele caldo de inovações que se formaram os primeiros grupos psicodramáticos de orientação psicanalítica para crianças e adolescentes.

Da França, o psicodrama analítico chegou à Argentina, tendo sido acolhido e desenvolvido pelo psicanalista e dramaturgo Eduardo Pavlovsky (1974, 1976, 1982). Dali para a frente, as articulações teóricas e as experiências grupais passaram a dar maior ênfase à emergência da criatividade, entendendo que a terapia não deveria estar apenas voltada para a resolução de conflitos, mas também para favorecer a potência criativa. Naquele então, a influência da teoria do amadurecimento emocional de Donald Winnicott foi decisiva para compor com o legado das experiências grupais que chegavam da França.

Ainda referidos ao campo histórico das origens do tratamento grupal com crianças, temos a forte influência exercida por Pavlovsky no trabalho desenvolvido por Alícia Fernández (1989) no campo psicopedagógico. Essa autora argentina iniciou seus estudos em Psicopedagogia e quase, concomitantemente, realizou a formação grupal psicodramática com Pavlovsky. Ela buscava construir ferramentas teóricas para formular uma teoria psicopedagógica que, na época, ainda estava muito baseada numa visão reeducativa e carecia de um referencial clínico $^{2}$ sobre a aprendizagem.

De mãos dadas com Sara Paín (1988), uma das pioneiras da Psicopedagogia Clínica, e Pavlovsky, aliando 
técnicas psicodramáticas ao tratamento de crianças com problemas de aprendizagem, Alicia Fernández vem construindo uma teoria que considera a aprendizagem uma atividade integrada, desde sua origem, aos aspectos lúdicos/subjetivos e objetivos/cognitivos da subjetividade.

Inspirados em sua obra, nosso trabalho vem se desenvolvendo na Clínica de Atendimento Psicológico da UFRGS, desde 1994, com ênfase no atendimento individual de crianças e adolescentes com problemas de aprendizagem, e estamos iniciando um trabalho grupal que pretendemos incrementar com o projeto de pesquisa Tratamento Grupal Psicopedagógico e as Cenas Temidas na Aprendizagem de Crianças e Adolescentes.

Entendemos que o trabalho psicopedagógico deve propiciar atividades que permitam construir ou reconstruir capacidades lúdicas sempre que estas estiverem dificultadas, pois é desses mananciais de transformação que emergem a curiosidade e as operações cognitivas necessárias para elevar os patamares do pensamento. Deve, também, possibilitar o desenvolvimento de cenas que digam respeito ao aprender, principalmente, aquelas que ficam aderidas de forma rígida e estereotipadas, gerando culpa e vergonha.

\section{A especificidade do trabalho grupal psicopedagógico}

O espaço grupal permite criar certa distância confiável entre aquele que apresenta determinada dificuldade ou sofrimento e seus pares. Ao relatar alguma situação vivida, esta deixa de ser propriedade exclusiva do relator, e todo o grupo se apropria dela. O trabalho de relatar é muito valorizado para os objetivos da Psicopedagogia, pois a criança com dificuldades de aprendizagem, muitas vezes qualificada como passiva, assume um papel ativo perante os pares. Ao mesmo tempo em que relata pode se apropriar de outra maneira da cena vivida, facilitando a abertura de um espaço para pensar e transformar sua própria história. Por sua vez, o relatar produz um entrecruzamento de escutas das outras crianças e dos coordenadores do grupo, favorecendo, pelo menos, dois movimentos concorrentes: do lado daquele que enuncia e como efeito de comunicar ao outro, pode propiciar o reencontro, na fala ou no gesto do outro, com partes desconhecidas de si próprio e, por isso mesmo, poder ser rico material para desenvolver novas intuições. Do lado de quem recebe, o encontro

4 Estilos clin., São Paulo, v. 18, n. 3, set./dez. 2013, 490-507. 
com a diferença do outro pode abrir espaços de identificação e de descobertas de aspectos até então não pensados de si próprio.

Mais facilmente do que no atendimento a uma só criança, o tratamento grupal permite trabalhar a relação entre os membros do grupo, pela via de suas narrativas, seus pactos, suas fidelidades, suas obediências e suas descargas coletivas.

À diferença de situações pedagógicas, o grupo não trabalha diretamente com os conteúdos escolares, mas a partir dos mesmos, sempre que trazidos pelas crianças. Assim, a dificuldade de ler pode se manifestar, no grupo, através de uma série de operações de disfarce. A proposta do trabalho terapêutico, nesse sentido, não será criar didáticas mais adequadas, mas sim abrir espaços nos quais a criança possa se reconhecer nas leituras que já realiza para, a partir dali, criar nexos com outras leituras possíveis.

Os grupos terapêuticos também podem ser caracterizados como invenções de tempo e de espaço. No grupo, cada participante pode se escutar naquilo que diz ler suas produções, surpreender-se com alguma invenção. É também uma invenção de espaço, pois trata de um convívio original com outras crianças e adultos. Não se assemelha à sala de aula, nem ao convívio com a família. Ao mesmo tempo em que propõe uma zona diferenciada, não deve ser um espaço imaginário, onde tudo é possível, tudo é permitido. Se uma criança apresenta dificuldades em suas aprendizagens, não cabe ao grupo negá-las, ao mesmo tempo em que não se encaminham as questões do ponto de vista moral, do que é certo ou errado, do que se deve ou não fazer. $\mathrm{O}$ objetivo é estritamente terapêutico e, em Psicopedagogia, o caminho do tratamento visa abrir espaços de autoria de pensamento, de tornar pensáveis as experiências vividas.

\section{Cenas temidas no campo da aprendizagem}

Para fins dessa pesquisa, definimos cenas temidas como temores, experiências que marcam negativamente a capacidade de se reconhecer pensando, angústias diante da aprendizagem, aspectos exigidos pelo ensino formal ou informal, mas aos quais a criança ou o adolescente não se sente capaz de responder. Em geral, esses sentimentos não são de todo conscientes, gerando fuga das aprendizagens.

Voltando ao exemplo da leitura - ou de sua impossibilidade - a criança pode encontrar nos pares formas de esconder sua dificuldade, 
apoiando-se de forma passiva e automática em outra criança que domina a leitura.

Cabe aos coordenadores do grupo a tarefa de observar as defesas e os comportamentos que evitam se confrontar com as dificuldades de aprendizagem e criar um espaço onde essas possam ser reconhecidas, aceitas e pensadas.

Não estamos nos referindo especificamente ao domínio de conteúdos escolares, mas ao reconhecimento de autoria de pensamento, que está na base de toda a aprendizagem saudável. Toda manifestação de autonomia e curiosidade pressupõe um sujeito autor, capaz de se reconhecer pensando.

A palavra cena, que participa do título da pesquisa, possui duas vertentes etimológicas. Do latim, scaena, faz referência a cenário ou teatro, o lugar onde se mostra algo para o outro. Do grego, escena, faz referência a montagens temporárias, como as tendas nômades, que servem para um alojamento breve, durante as travessias. Em ambos os sentidos, a cena é uma construção que envolve uma relação com os outros. Seus movimentos serão descritos na metodologia.

Pensar em cenas, por sua vez, não faz referência, necessariamente, a um ambiente externo e, sim, pressupõe uma forma de pensar clinicamente. Diz respeito a um modo de escutar, uma postura, uma atitude clínica que pressupõe abrir um espaço entre o que vemos e o que o outro ou o mundo nos mostra. Essa observação inclui não apenas palavras, mas corpos, imagens, movimentos, gestos. Permite a espacialização, ajuda a construir novas fronteiras que favorecem distanciar-se do drama pessoal. Na situação terapêutica, diz respeito a introduzir jogos que possibilitam reconstruir cenas da vida pessoal de um ou mais participantes, para que possam ser trabalhadas pelo grupo. As cenas dramatizadas facilitam a enunciação dos conflitos, favorecendo a que a culpa vá dando lugar à recordação e a uma mobilização de capacidades de pensamento.

\section{Objetivos}

Como objetivos precípuos, a pesquisa pretende:

- Realizar um levantamento das cenas mais frequentes trazidas pelos jovens e que digam respeito às suas dificuldades de aprendizagem. 
- Formar um arquivo de cenas que servirá como material para a criação de jogos dramáticos e atividades lúdicas, sempre que o surgimento de situações temidas possa sugerir a eficácia da utilização dos mesmos.

\section{Metodologia: sujeitos, instrumentos $e$ procedimentos}

Em sua primeira versão, a pesquisa abrangeu dois grupos de crianças, um deles atendido na Clínica de Atendimento Psicológico da UFRGS e outro, em uma escola pública.

A indicação de tratamento grupal psicopedagógico foi precedida de avaliação individual, levando-se em consideração fatores como proximidade de idade, uma não discrepância em termos de estruturação psíquica entre os participantes e o fato de trazerem problemáticas cuja semelhança sugeria um bom prognóstico em termos de trabalho grupal.

Cabe ressaltar que integraram a pesquisa somente aqueles participantes que assim o desejaram e que foram autorizados por pais ou responsáveis.

Para a formação dos grupos, observaram-se as indicações propostas por Pavlovsky (1974) e Fernández (1984), segundo as quais o grupo não deve ter mais de oito componentes, sendo a equipe terapêutica formada por 
um coordenador e um coordenador auxiliar. Foram estabelecidas quatro categorias de idade para a formação dos grupos, sendo que a diferença de idade dos integrantes de cada grupo não podia exceder três anos: de 5 a 8 anos - princípio de latência; de 8 a 11 anos - fim de latência; de 11 a 13 anos - pré-adolescência; de 13 a 16 anos - adolescência.

Nos grupos que coordenamos, todos os participantes tinham entre 11 e 13 anos de idade, estando, portanto, inseridos na faixa etária da pré-adolescência, segundo as categorias expostas acima.

O grupo da clínica não possuía uma configuração fechada, embora esta fosse estável. Participantes novos poderiam entrar e antigos poderiam sair, não havendo um limite fixo para o número de encontros. Esse critério de mobilidade dentro do grupo representou um fator terapêutico importante, por permitir trabalhar a flexibilização nas relações e nas aprendizagens, bem como as fantasias e temores em face das perdas e da presença da novidade.

$\mathrm{Na}$ escola pública, por sua vez, por questões de contrato com a equipe dirigente da mesma, o grupo possuía uma configuração fechada e o número de encontros foi determinado previamente em oito sessões.

Em ambos os grupos, a realização dos encontros era semanal, tendo uma hora e meia de duração cada encontro.

Foram utilizadas notas de campo para o registro dos encontros dos grupos, bem como foram feitas fotografias das produções dos participantes. As coordenadoras dos grupos - uma psicóloga da Clínica de Atendimento Psicológico da UFRGS e uma aluna de graduação em Psicologia, que compartilham a autoria do projeto - se reuniam semanalmente com a coordenadora da pesquisa para discutir e supervisionar o trabalho realizado e pensar em estratégias futuras. A partir dessas supervisões, eram criadas propostas de atividades a serem realizadas pelos grupos.

\section{Procedimentos de análise dos dados}

Os pesquisadores utilizaram a ferramenta clínica do pensar em cenas para construir o corpo da pesquisa. Pensar em cenas supõe:

Movimento de abrir espaços para que a palavra ou o gesto, em geral não conscientizados por aquele que enuncia, possam sair do circuito da angústia e da culpa. 
Suspender julgamentos que obstaculizam a capacidade de pensar, sem negar a dificuldade que se apresenta.

Pensar em cenas que abram espaços para perguntas, exercício da curiosidade.

Estabelecer, junto com o grupo, nexos de elaboração objetiva e subjetiva dos temas trazidos.

As pesquisadoras se reuniram para reler e discutir os relatos dos atendimentos grupais, buscando recortar, do material, as cenas temidas trazidas pelos participantes em relação às dificuldades de aprendizagem.

\section{Resultados e discussão}

Os resultados da pesquisa serão discutidos a partir de algumas cenas temidas levantadas nos grupos. Não constitui objetivo da pesquisa analisar, separadamente, os dados do grupo realizado na clínica e na escola pública, mas sim considerá-los conjuntamente em termos das cenas temidas do aprender trazidas pelos participantes. Para facilitar a discriminação dos grupos, os intitularemos grupo A e grupo B.

Em nossa experiência, observamos que os integrantes do grupo revivem, no espaço terapêutico, limitações muito semelhantes às enfrentadas na escola, na família e nos ambientes de aprendizagem em geral. Por ser um trabalho grupal, aqueles que têm dificuldades em algum campo - leitura, por exemplo - se aliam aos pares que não apresentam a mesma limitação para realizarem as atividades propostas entre eles. A cena a seguir ilustra essa observação.

Os participantes do grupo A, João, Carolina, Patrícia e Tiago (nomes fictícios) estão envolvidos em um jogo de mímicas que implica a leitura de cartões com palavras a serem descobertas pela equipe a partir de mímicas. As meninas apresentavam dificuldades na leitura e escrita, enquanto os meninos não tinham essas limitações. Observou-se que, quando precisavam ler os cartões para realizar a mímica da palavra, tanto Carolina quanto Patrícia buscavam amparo nos meninos, pedindo que estes lessem os cartões para elas, ou então procuravam formar duplas com eles ao jogar. Isso ocorreu diversas vezes, até que, em supervisão, foi visto que não poderíamos produzir no grupo um espaço imaginário em que as dificuldades das meninas com a leitura fossem negadas ou desconsideradas, pois isso implicaria que elas permanecessem dependentes dos meninos, sem encontrar saídas saudáveis para suas dificuldades.

Tornou-se necessário, assim, pensar em intervenções e promover um espaço onde essas limitações pudessem ser reconhecidas e trabalhadas num enquadre que, sem ser um ambiente de ensino, visasse, todavia, promover aprendizagem. Era preciso utilizar uma consigna suficientemente fechada, que não provocasse um excesso de ansiedade, e ao mesmo 
tempo suficientemente aberta, para permitir a criação.

Pensou-se em uma proposta de atividade envolvendo a escrita do nome próprio e do nome de pessoas próximas, algo que costuma ser bastante familiar às crianças. Assim, na sessão seguinte, a proposta seria fazer com que cada participante desenhasse sua árvore genealógica, escrevendo os nomes das pessoas de sua família, bem como seu nome próprio. Essa atividade procurou eliciar o confronto com a escrita, mas a partir de algo que fizesse sentido para as crianças. Conforme mencionado anteriormente, é na operação de fazer sentido que o espaço mental do aprender associa-se ao espaço mental do brincar.

Cecília, uma participante nova, se integrou ao grupo. Também apresentava queixas de dificuldades de leitura e escrita. Reproduziremos um diálogo entre Carolina e Cecília, sendo que nenhuma das meninas tinha conhecimento das dificuldades apresentadas pela outra. Após a coordenadora fazer a proposta da atividade, seguiu-se a seguinte cena:

Cecília diz para Carolina, estendendo-lhe uma folha em branco: "Ó, duvido que tu saibas escrever meu nome. Ninguém escreve meu nome certo". Desafiada pela nova parceira de grupo, Carolina reluta, mas, diante da insistência de Cecília, aceita o desafio e põe-se a escrever. Ao terminar, Carolina mostra o que escrevera (Cesilia) para Cecília: "Eu acho que é assim”. Cecília diz: "Ah, eu sabia! 
Ninguém escreve o meu nome certo. Mas tu escreveste quase certo. Tu errou aqui (aponta para o S), que é com a letra $C$, e aqui (aponta para o primeiro I), que tem acento. Eu sempre tenho que explicar pras pessoas como se escreve o meu nome".

A partir daquele momento, Carolina e Cecília se aventuram a escrever o nome das pessoas de sua família, explicando a elas mesmas e às coordenadoras suas hipóteses em relação à escrita desses nomes e permitindo que fossem, então, trabalhadas suas ideias a respeito das relações entre os diferentes fonemas e suas representações.

Ao final da sessão, Carolina escreveu, pela primeira vez, seu nome no quadro da sala (algo que os outros integrantes faziam desde o primeiro encontro, e que ela se negava a fazer). Em momentos posteriores no grupo, Carolina passou a resistir menos em situações nas quais se via diante de suas dificuldades de leitura e escrita. Chegou a oferecer-se, em determinada ocasião, para criar uma tabela no quadro e nesta escrever as "pistas" envolvidas em uma determinada atividade.

No recorte acima, além de uma cena temida do aprender, também é possível observar o potencial terapêutico das relações entre pares no espaço grupal, as quais ajudam a valorizar a função positiva da ignorância. Carolina, inicialmente, estava presa ao lugar de não saber, mantendo-se em uma posição passiva em relação a seus companheiros de grupo que dominavam a escrita e a leitura, e destituindo-se de qualquer autoria. A cena temida, aqui, seria defrontar-se com esse não saber, o que era evitado e, ao mesmo tempo, mantinha a menina em uma posição de dependência. Ao ser instigada por Cecília a escrever o nome desta, Carolina arrisca-se a escrever, talvez encorajada pela observação da parceira de que ninguém sabia escrever seu nome certo, o que ajudou a relativizar a culpa pelo erro. Consegue, assim, fazer uma apropriação mais sadia do não saber em direção ao saber.

Em outra ocasião, (grupo B), da qual participavam Luciana e Bernardo, foi observada a presença de uma nova cena temida relacionada ao aprender. Foi proposta à dupla a criação de tarefas para uma gincana escolar. Eles deveriam pensar em atividades para uma turma de quarta série e para uma turma de sétima série. O objetivo era atualizar, no grupo, um tema surgido no primeiro encontro: atividades que eles poderiam fazer e outras que não poderiam fazer em sua idade, que remetia ao conflito entre ser considerado grande em algumas situações e pequeno em outras. Apesar de a proposta ser trabalhar em conjunto, Luciana e Bernardo não conseguiram fazê-lo, sendo que cada um pegou uma folha e trabalhou individualmente. 
Luciana propõe que uma das tarefas da gincana seja montar uma ponte de cartas, algo que não é aceito por Bernardo, que julga ser esta uma atividade impossível de ser realizada. Luciana se angustia ao ver que Bernardo enumera diversas tarefas, enquanto com ela nada ocorre ("não consigo pensar em nada"). Refere: "Ai, sora, me ajuda, ele já tem um monte de tarefas e eu só tenho uma”. Aqui aparece uma cena temida, razão pela qual a coordenadora estimula Luciana a falar sobre o fato de "não conseguir pensar, dar um branco". Ela refere que "as ideias não vêm, esforça-se para pensar e não consegue" e que isso ocorre nas provas algumas vezes. Segue-se o seguinte diálogo:

Coordenadora: "Como é quando não conseguimos pensar e vemos os outros tendo várias ideias?"

Luciana: "É horrível, sora, me acho uma burra. Soôra, me ajuda a pensar".

Coordenadora: "Como posso te ajudar a pensar?"

Luciana: "Me dando ideias de tarefas."

Luciana segue angustiada ao ver Bernardo enumerando mais tarefas, mas consegue propor mais algumas. Ele critica boa parte delas; Luciana, por sua vez, não sustenta suas sugestões e não usa argumentos, cedendo facilmente às objeções de Bernardo, que, por sua vez, não pede a opinião de Luciana sobre as tarefas que propõe. Vai aumentando a lista, entusiasmado com suas ideias.
Vemos, aqui, como Luciana duvida de sua possibilidade de pensar. O contato com a produção do outro produz nela um efeito paralisador, que impossibilita se reconhecer autora de seu pensamento. Até mesmo em sua descrição de como poderia ser ajudada, observa-se sua desapropriação de um lugar de autoria: é o outro que lhe daria ideias de tarefas, as quais viriam de fora. Aqui temos pistas de como se configura, para Luciana, "o efeito do outro em mim", descrito por Alicia Fernández. As intervenções da coordenadora, nesse sentido, buscaram criar um "entre" Luciana e a cena que estava ocorrendo, tentando torná-la pensável.

Após reflexão entre o grupo de pesquisa, pensando no "efeito do outro em mim”, é proposto que eles retomem a tarefa da montagem da torre de cartas, indicada por Luciana para a gincana e considerada impossível por Bernardo. Ambos aceitam a ideia e começam a montar, cada um de sua forma, a torre. Luciana usa duas bobinas de papel higiênico como suporte e passa a dispor as cartas. A ponte desaba quando ela coloca cartas bem no meio. Segue-se o seguinte diálogo:

Luciana: "Não sei."

Bernardo: "Isso que eu falei que era impossível" (refere-se ao peso que as cartas fazem no meio, o que não mantém a ponte sustentada).

Luciana: "Não vai dar, tem que segurar."

Luciana tenta novamente e caem mais algumas cartas. 
Bernardo: "Viu?"

Luciana: "Mas eu consegui fazer."

Luciana refaz e a ponte fica por pouco tempo em pé.

Bernardo: "Não dá."

Luciana: "Ai sora, vai ser difícil."

Coordenadora: "É mais difícil do que tu pensavas, Luciana?"

Luciana: "É."

Coordenadora: "E tu Bernardo? Como tu acha que deve ser?"

Bernardo: "Eu vou colocando as cartas em forma de casinha" (caem as cartas). Nessa mesa não dá, eu vou pra outra" (vai para o outro lado da sala utilizar outra mesa. Ele alega que precisaria fazer isso em outra mesa, mais fixa, mas depois entendemos que ele estava com dificuldades para mostrar suas tentativas frustradas de montar a ponte).

Enquanto isso, Luciana continua tentando montar a ponte.

Luciana: "Não vai cair. Nada é impossível. Consegui fazer a ponte. Bernardo!" (chamando-o para ver a ponte).

Coordenadora: "Qual foi a estratégia para montar?"

Luciana: "Tem que colocar peso no rolo para não cair. E tu, Bernardo, disse que era impossível."

Os dois passam a discutir o que era necessário para fazer a ponte. Nesse momento trabalham cooperativamente no grupo pela primeira vez. Aumentam o número de rolos e a extensão da ponte. Uma carta, acidentalmente, vira para o lado e Bernardo tem a ideia de fazer uma ponte em círculo. Luciana concorda e eles fazem juntos a ponte em círculo (abaixo).

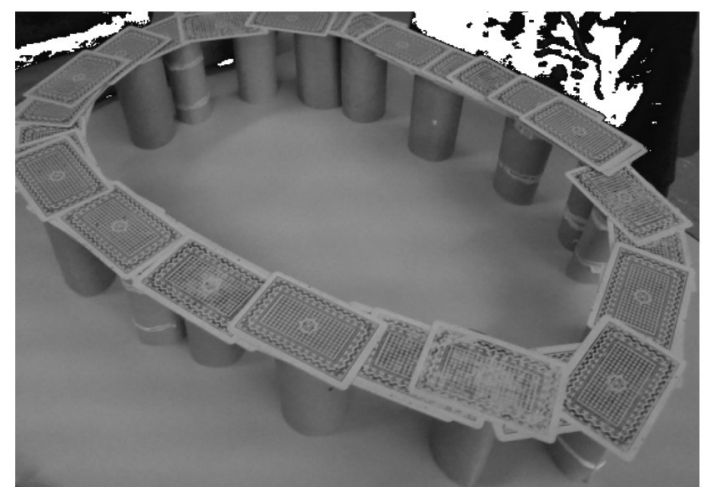

Coordenadora: "Muito legal a ideia de vocês." 
Luciana: "A ideia foi do Bernardo."

Surpreende as coordenadoras a retirada que Luciana faz de qualquer autoria sobre a ponte. Com frequência, nas atividades, Luciana se colocava no lugar de não saber, de forma que nem mesmo ela percebia o quanto estava se desresponsabilizando por aquilo que ela mesma produzira. Esse lugar de não saber de alguma forma a protegia de possíveis conflitos que a bloqueavam no reconhecimento de si em relação ao outro. De forma onipotente, Luciana se eximia daquilo que a diferenciava do outro, conforme se observa no seguinte diálogo:

Coordenadora: "Ah, é? Quem teve a ideia de fazer a ponte?"

Luciana: "Foi o Bernardo."

Coordenadora: "E a ideia de construir a ponte de cartas?"

Luciana: "Foi o Bernardo?"

Bernardo: "Foi ideia da Luciana,"

Coordenadora: "Parece que a Luciana não está conseguindo reconhecer que foi ideia dela."

Luciana: "É que a ideia não foi minha, eu vi na TV."

Aqui podemos novamente perceber a dificuldade de Luciana em reconhecer-se autora, confundindo sua capacidade de pensar com exclusividade de ideias.

A partir do recorte acima, também cabe discutir a relação que esses integrantes mantinham com os obstáculos que encontravam ao longo do processo de aprendizagem. Tanto Luciana como Bernardo manifestaram maneiras diferenciadas de lidar com as suas dificuldades e de expressá-las. Luciana resistia a reconhecer seus potenciais de pensamento e verbalizava a impossibilidade de reconhecer-se autora, o que também se manifestava em uma dificuldade de assumir a singularidade de suas ideias. Já Bernardo manifestava, em ato, a forma como lidava com suas limitações, como quando se retirou da mesa onde estávamos com intenção de montar em outro lugar sua casa de cartas, para ficar longe dos olhares dos outros e da possibilidade de expor seu "fracasso".

\section{CONCLUSÕES}

A partir das cenas recortadas, foi possível discutir as diversas dificuldades que a aprendizagem pode colocar em questão, que se manifestam, muitas vezes, em cenas temidas relacionadas ao aprender. Por tratar-se de um processo que não acontece apenas no espaço individual e, sim em um espaço "entre", que envolve o sujeito, o outro e o objeto de conhecimento, o aprender pode fazer com que o sujeito se interrogue sobre seu fazer no mundo.

Nesse sentido, o espaço terapêutico grupal tem se mostrado um terreno fértil para o trabalho clínico psicopedagógico, que possibilita abrir espaços de pensar e cria oportunidades para que as crianças se reconheçam autoras de seu pensamento. Nos dois grupos, percebeu-se a extrema importância da 
intervenção psicopedagógica sobre as manifestações de ocultamento do sujeito criador/autor.

A partir de Fernández (1989), é possível salientar a modalidade de aprendizagem como algo que caracteriza a forma como o sujeito se apropriará do objeto, e esta forma singular é constituída na e pela trajetória de relações estabelecidas durante a vida. Uma modalidade de aprendizagem muito observada, nos dois grupos, é aquela em que o sujeito se esconde, tanto na forma de ação corporal como através da palavra. Isso trouxe como efeito um bloqueio do enfrentamento com o novo e a reprodução de modelos, evidenciados pela dependência estabelecida entre o sujeito e o saber do outro, que o impede de fazer sua própria leitura do mundo e construir suas próprias hipóteses.

Essas modalidades contribuíram para o surgimento, no grupo, de diversas cenas temidas relacionadas ao aprender caracterizadas pelas tentativas dos participantes em ocultar suas limitações.

Acreditamos que, trabalhar as cenas temidas da aprendizagem, no contexto grupal, proporciona interessantes aberturas de espaços criativos para o sujeito e entre os pares, bem como auxilia a capacidade de perceber a diferença entre o eu e o outro, ao mesmo tempo em que amplia a capacidade de perceber-se incompleto em relação ao outro. Constatamos, cada vez mais, a necessidade de dar continuidade ao atendimento grupal 
como importante ferramenta de apoio para o enfrentamento das dificuldades no aprender. Sabe-se que as cenas temidas constituem todo o processo de desenvolvimento humano e, quando trabalhamos com as dificuldades de aprendizagem com crianças e adolescentes, é crucial fazermos com que esses obstáculos, que são as cenas temidas, apareçam, para resgatar, de forma lúdica, a capacidade e a possibilidade do conhecer.

THERAPEUTIC GROUP APPROACH AND THE FEARFUL SCENES OF LEARNING IN CHILDREN AND ADOLESCENTS

\begin{abstract}
The research aims at studying the fearful scenes of learning in therapeutic groups of children and adolescents between 11 and 13 years old. During the process of the groups and by identifying the "fearful scenes" of learning it was possible to reflect the obstacles of each participant. The authors of the project created play activities to allow the reflection of each one's own difficulties and capacities in order to recognized one's own creative processes. In this article we show how the scenes were thought and performed. The authors point to the importance of the group intervention mainly when the manifestations and recognition of creativity are bidden for the participants of the group.
\end{abstract}

Index terms: learning; fearful scenes of learning; learning disabilities; children; adolescents.

GRUPO DE TRATAMIENTO PSICOPEDAGÓGICO Y ESCENAS TEMÍA EL APRENDIZAJE DE LA NIÑEZ Y LA ADOLESCENCIA

\title{
RESÚMEN
}

Esta investigación tubo como objetivo estudiar las escenas temidas en el apredizaje de niños y adolescentes, de 11 a 13 anõs, que estabam en tratamiento psicopedagógico en grupo. A partir de la identificación de las "escenas temidas" en el grupo fué posible pensar sobre los obstáculos encontrados por los participantes. El equipo de psicopedagogos estructuró actividades lúdicas para provocar la confrontación de cada participante con él mismo y en relación al otro, con el objetivo de hacerlo pensar sobre sus dificultades y permitir que asumieran sus capacidades creativas. Relatamos algunas de las escenas y la forma como fueron pensadas por el equipo de psicopedagogos. Se percibió la importancia de la intervención psicopedagógica grupal sobre las manifestaciones de ocultación del sujeto creador/autor. Estas manifestaciones fueron las que más caracterizaron la forma como los participantes se relacionabam con el objeto del conocimiento.

Palabras clave: aprendizaje; escenas temidas del aprender; psicopedagogía; niños; adolescentes.

\section{REFERÊNCIAS}

Anzieu, D. (1982). El psicodrama analítico en el niño y en el adolescente. Buenos Aires: Paidós.

Dolto, F. (2005). A causa das crianças. São Paulo: Ideias e Letras. (Trabalho original publicado em 1981)

Fernández, A. (1984). Tratamiento grupal de los problemas de aprendizaje. Temas de Psicopedagogia, Anuário. Buenos Aires.

506 Estilos clin., São Paulo, v. 18, n. 3, set./dez. 2013, 490-507. 
Fernández, A. (1989). A inteligência aprisionada. Porto Alegre, RS: Artes Médicas. Freud, S. (1969). Análise de uma fobia em um menino de cinco anos. In S. Freud, Edição standard brasileira das obras psicológicas completas de Sigmund Freud. (J. Salomão, trad., Vol. 10, pp.13-156). Rio de Janeiro: Imago. (Trabalho original publicado em 1909)

Klein, M. (1979). La técnica psicoanalítica del juego: su historia y significado. In M. Klein, Obras Completas de Melanie Klein. Buenos Aires: Paidós-Horme. (Trabalho original publicado em 1953)

Paín, S. (1988). A função da ignorância. Porto Alegre, RS: Artes Médicas.

Pavlovsky, E. (1974). Psicoterapia de grupo en niños y adolescentes. Buenos Aires: Busqueda.

Pavlovsky, E., Frydlewsky , L., \& Kesselman, H. (1976). Las escenas temidas de un coordinador de grupos. Clinica y análisis grupal, 1(1), 1-9.

Pavlovsky, E. (1982). Processo creador. Buenos Aires: Busqueda.

Winnicott, D. (1993). Os processos de maturação e o ambiente facilitador: estudos para uma teoria do desenvolvimento emocional. Porto Alegre: Artes Médicas. (Trabalho original publicado em 1975)

\section{NOTAS}

1. Função positiva da ignorância é um conceito introduzido por Sara Paín (1988) para designar o contato com o desconhecimento e que serve como o principal motor para as descobertas.

2. O termo "clínico" é um adjetivo que faz referência a uma postura, uma ética, um modo de ler e intervir nas situaçóes de aprendizagem, que levam em consideração não apenas os aspectos objetivos do conhecimento, mas também as significaçóes atribuídas ao aprender (Psicopedagogia Clínica).

clinicap@ufrgs.br

Avenida Protásio Alves, 297/ $3^{\circ}$ andar 90410-000 - Porto Alegre - RS - Brasil.

vdarriba@centroin.com.br Rua Marquês de São Vicente, 17/207 - Bloco 2 22451-041 - Rio de Janeiro - RJ - Brasil. 